\title{
History of geography (not identical to historical geography)
}

\section{Federico Ferretti \\ University College Dublin \\ federico.ferretti@ucd.ie}

\begin{abstract}
This entry does not pretend exhaustivity in summarizing the bourgeoning field of current international scholarship in the history of geography. It does not even pretend to be a compendium of any possible narrative to be defined a "history of geography". Rather, it will focus on some current methods and research tools in the broadly defined area of the philosophy and history of geography. This way, it will provide the reader with the most relevant updates to understand why this "subdiscipline", which is still considered as a relatively peripheral one by several geographers, is showing special vibrancy in the last years. This renewed interest in geography's histories is based on the increasing extension of the places, periods, authors and definitions which are currently investigated by scholars, who generally use the theoretical and methodological tools of the spatial turn and of contextual readings in the history of science that successfully challenged internalism, essentialism and positivism in reading the geographical traditions. An important part of current scholarship is now committed to radicalize, internationalize and decolonize the histories of geography, by increasingly addressing the richness, complexity and diversity of a plurality of "geographical traditions" rather than one "geographical tradition".
\end{abstract}

\section{Introduction}

In their recent entry on the "History of Geography" for the Elsevier Encyclopedia of Human Geography, Michiel van Meeteren and James Sidaway highlight the fact that, despite still being considered by several geographers as a relatively specialized sub-disciplinary niche, the history of geography is showing a remarkable vibrancy (Van Meeteren \& Sidaway, 2020). The general

F. Ferretti, 2021, "History of Geography (not identical to historical geography)", in D. Richardson et al. The Wiley-AAG International Encyclopedia of Geography: People, the Earth, Environment, and Technology. Hoboken: Wiley and AAG, https://onlinelibrary.wiley.com/doi/10.1002/9781118786352.wbieg2105 [Pre-Print Author version] 
relaunch of this field of study is accompanied by the close engagement of its scholars with broader debates in geography, as well as in the wider area of human and social sciences. These current conversations can be often associated to what historians of science call the periodical coming back of "old" ideas (such as environmental determinism, to give one of the most classical examples for geography), which reignite past debates under new forms and in new arenas. Historians of geography claim that they still have a lot to say on matters of natures-cultures, big data, the Anthropocene, and ideas on catastrophe especially referred to anxieties around climate change, to give just a short summary of the most recent scholarly and political debates in which authors and ideas that characterized geography's pasts are explicitly or implicitly remobilized.

Another point that is stressed by Meeteren and Sidaway, one which matches critical scholarship discussing the elaboration of "canons" in the discipline (Keighren, Abrahamsson \& Della Dora, 2012), is about the plurality and diversity of geographical traditions. The heterogeneous nature of geographical knowledges and of their places of production is increasingly shown by works calling for a more inclusive understanding of knowledges which might have been produced outside the most current, traditional and canonized places where scholarly notions are build, such as official academies. Yet, "other geographical traditions" well existed outside universities and established academic canons, in cultural and linguistic areas beyond the dominant Northern and AngloAmerican ones, and in historical periods which might have preceded the institution of geography as an academic discipline. It is worth noting that this last phenomenon is relatively recent for most of countries, as it took place between the nineteenth and the twentieth century (Ferretti, 2019).

To make sense of this forcedly short state-of-the-art, this entry first discusses the depth and diversity of geography's pasts. Then, it analyses some of the most current methodological focuses such as contextualism, transnationalism and the spatial turn. Finally, it contributes to current understandings of the history and philosophy of geography by addressing some possible future directions that international scholarship is taking. These are especially associated with a

F. Ferretti, 2021, "History of Geography (not identical to historical geography)", in D. Richardson et al. The Wiley-AAG International Encyclopedia of Geography: People, the Earth, Environment, and Technology. Hoboken: Wiley and AAG, https://onlinelibrary.wiley.com/doi/10.1002/9781118786352.wbieg2105 [Pre-Print Author version] 
radicalization, a diversification and a decolonization of the histories of geography as they emerge from the most updated literature.

\section{A longer tradition and an interdisciplinary field}

As most of geography's historian recognize, the production of scientific knowledge carrying explicitly the label of "geography" dates from the Ancient Greece. Indeed, some authors of the Antiquity produced notions which outstandingly predated several debates in the history of geography. A partial list of these concepts and problematics might include the issue of defining region, space and place, the signification of the historical and cultural diversity of peoples inhabiting different lands, and the possible roles that different climates or environments might have played in diversifying their histories. Furthermore, in the earliest geographical encyclopedia which (almost fully) survived, that is the 17 volumes of the Geography authored by Strabo in the first century $\mathrm{AD}$, one can find the earliest occurrences of what we know today as the debates contrasting "quantitative" and "qualitative" methods in geography. It was especially the case with Strabo's critiques to Eratosthenes, who was famously the author of the first astronomic measurement of the terrestrial meridian. Despite considering Eratosthenes's works as exceptional accomplishments, Strabo noticed the limited nature of a geography that was essentially, if not uniquely, preoccupied with astronomic and terrestrial measurements and calculations. Conversely, for Strabo, the work of the "geographer" should go far beyond that of the "surveyor", by addressing a very wider range of matters and methods which still characterize what is called today human, social, cultural, political and regional geography (Farinelli, 2020).

In fact, Strabo dedicated his 17 volumes to the description of the totality of the world that was considered to be inhabited at that time, which he called the Ecumene, stating a privileged interest for human and political matters rather than for the "heavens". This interest included theory: Strabo's initial two volumes, the Prolegomena, constituted a true theoretical and historical introduction to what we would call today the "discipline" of geography. This introduction contains outstanding statements such as: "No science more than geography is a philosophers' affair"

F. Ferretti, 2021, "History of Geography (not identical to historical geography)", in D. Richardson et al. The Wiley-AAG International Encyclopedia of Geography: People, the Earth, Environment, and Technology. Hoboken: Wiley and AAG, https://onlinelibrary.wiley.com/doi/10.1002/9781118786352.wbieg2105 [Pre-Print Author version] 
(Strabo, Geography, I, I, 1). This strong association between geography and philosophy was motivated on historical grounds: several names which are known by historians of philosophy and literature as early Greek writers and thinkers such as Anaximander, Hecataeus, Democritus, Eudoxus, Ephorus, Polybius, Poseidonius and others (even including Homer) are mentioned by Strabo as the earliest geographers, with the aim of defining geography as a highly ambitious form of knowledge, one which was indispensable for making sense of the world. To Strabo, this first occurred through the knowledge of the different countries and their resources, which was also part of a civic duty. To this end, geography had to help in the: "Great art of living and being happy" (Strabo, Geography, I, I, 1).

While one would struggle to find a more flattering definition of the importance of geographers' works even today, it is worth noting that this definition was mainly referred to the usefulness of knowing the world for political purposes. It was also for these reasons that, across the centuries, Strabo's work has been periodically rediscovered and reinterpreted as an inspiration for later authors. It was especially the case with some geographers of the nineteenth century who are often included among the forerunners of what is called today a "critical geography": among others, Carl Ritter (1779-1859), Alexander von Humboldt (1769-1859) and Elisée Reclus (1830-1905). Although adapting their theoretical tools to diverse and even contrasting political agendas, these authors considered geography as a political tool to transform the society. While they worked before the constitution and academic separation of what we call today different scholarly "disciplines", another of their important contributions was the idea that a close link should exist between a field of study that may be defined "geography" and a field of study that may be defined as "history". Eventually, they explicitly defined geography and history as the two sides of the same investigation, of which space and time should be both key and consubstantial components, a statement which was famously echoed by other nineteenth century intellectuals such as French historian Jules Michelet (1798-1874).

F. Ferretti, 2021, "History of Geography (not identical to historical geography)", in D. Richardson et al. The Wiley-AAG International Encyclopedia of Geography: People, the Earth, Environment, and Technology. Hoboken: Wiley and AAG, https://onlinelibrary.wiley.com/doi/10.1002/9781118786352.wbieg2105 [Pre-Print Author version] 
This approach was part of their broader reference to the nineteenth century German philosophy of nature, more specifically the Naturphilosophie elaborated by authors such as Lorenz Oken (17791851) and Friedrich Schelling (1775-1854). This was a complex system of thinking that challenged ideas of a "divorce" between what was called "nature" and what was called "humankind" that was mainly inspired by Kantianism. This approach directly interested geographers such as Humboldt and Ritter, and later Reclus. While these latter's ideas on history and geography reflected the same consubstantiality of human and natural facts that was stated by the Naturphilosophen, it is worth noting that notions of humankind as being not superior or extraneous to nature, but rather a constitutive and consubstantial part of it, pre-dated several of the themes which are discussed under contemporary rubrics such as Anthropocene, hybridity, biogeography and natures-cultures. This confirms how reflecting on the ways in which "old" ideas resurface in being adapted to new social, intellectual and political contexts is extremely relevant today.

\section{Contextualizing and locating geography}

Until few decades ago, the history of geography generally appeared as a quite conservative and descriptive field, one which was often dedicated to the celebration of the accomplishments of "big men" belonging to the respective national schools, and of something like a linear progress leading to increasing "accurate" and "true" representations of the world. Critical scholarship has disrupted many of these approaches, starting by pioneering experiences such as the International Dialogue Project promoted by Anne Buttimer (1938-2017) and Torsten Hägerstrand (1916-2004) between the 1970s and the 1980s. Buttimer's endeavors showed to geographers the relevance of practices such as biography and autobiography in addressing the materiality and real lives of people who made the discipline, also beyond big names and beyond academies or canonized "Schools". This way, biography and autobiography started to highlight the need for considering contexts and places in the production of geographical knowledge.

F. Ferretti, 2021, "History of Geography (not identical to historical geography)", in D. Richardson et al. The Wiley-AAG International Encyclopedia of Geography: People, the Earth, Environment, and Technology. Hoboken: Wiley and AAG, https://onlinelibrary.wiley.com/doi/10.1002/9781118786352.wbieg2105 [Pre-Print Author version] 
This culminated with the adhesion of most historians of geography (and historical geographers) to the "spatial turn" of the social sciences. A special emphasis was put on fostering contextual readings of geographical texts produced in a certain historical period, highlighting the limitations of internalist readings in the history of ideas that only considered the (often positivistic) "evolution" from one idea to a more updated one. Indeed, these more "traditional" readings tended to neglect the wider intellectual, social and political contexts in which geographical ideas were produced, published and circulated. The notion of Geographical Tradition as discussed by authors such as David Livingstone (1993) has further overtaken these positivistic readings in the history of geography, being increasingly associated with spatially sensitive readings of disciplinary histories, highlighting the different reception and construction of similar scientific ideas in different places. These studies have also assumed the need for considering "ideas on the move", analyzing their circulation, intercultural transfers ad different receptions, through studies which are sometimes inserted in the theoretical framework of transnationalism.

These scholarly tendencies also opened the way to critical reassessments of geography's political roles, with a special emphasis on revealing the explicit or implicit political agenda of geographers who were directly involved in state and empire building. Indeed, all along the modern epoch, geography has played key political roles through its support to and complicity with European colonialism. This could occur through the so-called geographical "discoveries", exploration, surveying and map-making, but also through geography's participation in building colonial ideologies and Euro-centric propaganda. This was done through euro-centered maps, as well as through the spreading of racial prejudices on the people inhabiting the "tropics", who were considered as somehow "inferior" to White people on the grounds of environmental determinism. Reassessing the ways in which some of these contested notions are coming back in contemporary cultures, for instance about current anxieties for climate change, is one of the new and promising endeavors for the authors involved in these strands of study.

\section{Radicalizing and internationalizing geography's histories}

F. Ferretti, 2021, "History of Geography (not identical to historical geography)", in D. Richardson et al. The Wiley-AAG International Encyclopedia of Geography: People, the Earth, Environment, and Technology. Hoboken: Wiley and AAG, https://onlinelibrary.wiley.com/doi/10.1002/9781118786352.wbieg2105 [Pre-Print Author version] 
As noted by the latest reviews on current literature about the philosophy and history of geography that are periodically published in journals such as Progress in Human Geography and Geography Compass, the field of the history and philosophy of geography includes an increasing variety of diverse contributions that might have escaped from prevailing disciplinary canons. It is first the case with political dissidence (Keighren, 2018). While great work has been done in highlighting the "obscure" sides of geography's pasts, such as geographers' complicity with colonialism, warfare, social control and totalitarian regimes (to only give the most common examples), recent works focus instead on what can be called "other geographical traditions" (Ferretti, 2019). These include political dissidences, which were not always highlighted by early historians of geography (with some exceptions, however) due to the fact that political dissidents, exiles and scholars who were marginalized for political reasons, were not always in the condition of creating academic "schools", despite having been sometimes very influential through their published works. Yet, they were often discarded as "marginal" people, whose work was soon deemed "outdated" in the name of the same positivistic and institution-centered mood which has been challenged by the contextual and spatial-sensitive approaches that are discussed above. The clearest example in this rediscovery of different voices has been that of the anarchist geographers including Reclus, Peter Kropotkin and others, whose early works match wider strands of recent geographical scholarship on radical critical and anarchist geographies (Springer 2016).

However, anarchism is far from being the only example which is investigated by this recent scholarly wave. Radical, critical and feminist geographies which have been elaborated since the 1960s and 1970s, have recently been the object of several historical works, especially in North America, focusing on places, protagonists and intellectual contexts of scholars and activists in these fields (Barnes and Sheppard, 2019). The same might be said for several other critical and unorthodox approaches to geography, including anticolonialism, decolonization, postcolonialism and subalternity. A renewed attention is likewise being paid to those geographies which were produced in non-academic or non-institutional places and contexts, paralleling an increasing focus on archives (shared with historical geographers and historians of science) and to the critical

F. Ferretti, 2021, "History of Geography (not identical to historical geography)", in D. Richardson et al. The Wiley-AAG International Encyclopedia of Geography: People, the Earth, Environment, and Technology. Hoboken: Wiley and AAG, https://onlinelibrary.wiley.com/doi/10.1002/9781118786352.wbieg2105 [Pre-Print Author version] 
understanding of the archive not only as a "tank" of sources for fueling research, but as an object of study to be understood in its social roles. These roles of the archive might have included giving voice and privilege to certain voices while silencing others. Therefore, a critical approach to sources and archives is needed to understand places and contexts in the construction of knowledge, but also to be aware of the biases that the selection of these sources might imply for a research.

Among the neglected figures that are being rediscovered in the history of geography, it is worth noting the centrality of works reassessing female protagonists, such as gendered approaches to the discipline, considering how female voices are among those which were more often silenced. While this extends classical feminist historical geographies discussing the erasure of certain ways of producing knowledge (e.g. the reports of "lady travelers", texts that were considered as too "emotional" for being legitimated as "science"), current scholarship stresses the need for considering the multiple biases which penalized certain speakers. This was broadly the case with early non-conformist voices from people whose profiles, for various reasons, did not match the traditional stereotype of the white, male, middle-class academic (Jöns, Monk and Keigren 2017). Furthermore, international scholarship is trying to include, with the same "dignity" as others, authors and circuits that have been considered as "peripheral" in relation to the Anglo-American “core". This latter's monolingualism has often rendered invisible geographies which are produced in different places, including indigenous knowledge and scholarship which is published in languages that most of Anglophone readers do not bother to learn. It is also to challenge these kinds of monolingualism and parochialism and to "provincialize" the core that several contributions are focusing on geographical histories from outside the English-speaking world, including the Global South (Paiva and Roque de Oliveira 2020).

Finally, it is worth noting that groups of interest and research clusters in the history and philosophy of geography are committed to global networking and to organize periodical international meetings, promoting publications and trying to foster the transnational and cosmopolitan dimensions of their specialty, which is often associated with critical and radical approaches.

F. Ferretti, 2021, "History of Geography (not identical to historical geography)", in D. Richardson et al. The Wiley-AAG International Encyclopedia of Geography: People, the Earth, Environment, and Technology. Hoboken: Wiley and AAG, https://onlinelibrary.wiley.com/doi/10.1002/9781118786352.wbieg2105 [Pre-Print Author version] 
Among others, these tasks are performed by the History of Geography groups and commissions of the International Geographical Union, of the American Association of Geographers and of the Royal Geographical Society with Institute of British Geographers, as well as by vibrant regional networks such as Rede Brasilis in South America. The new scholarly directions which have been discussed above promise to be effectively the main guidelines towards the development and expansion of the field of philosophy and history of geography in the next future. If this will be the case, it would be allowed being optimistic on the further growth of this field and the increasing acknowledgement of its relevance for wider debates.

\section{SEE ALSO:}

- Commission History of Geography of the International Geographical Union (IGU): https://ugihg.hypotheses.org/

- History and Philosophy of Geography Research Group (HPGRG) of the Royal Geographical Society with Institute of British Geographers (RGS-IBG): https://hpgrg.org.uk/

- History of Geography Specialty Group of the American Association of Geographers (AAG): https://community.aag.org/communities/community-home?CommunityKey=e19863b851ce-4ef9-bb0b-72cfe14b0013

- Rede Brasilis, Rede Brasileira de História da Geografia e Geografia Histórica http://redebrasilis.net/

\section{References}

- Barnes, T.J. \& Sheppard, E. (Eds) (2019). Spatial histories of radical geography: North America and beyond. Hoboken, NJ: Wiley and Sons.

- Farinelli, F. (2020). Geografía. Mexico: UNAM.

- Ferretti, F. (2019) Rediscovering other geographical traditions. Geography Compass 13(3), e12421, https://onlinelibrary.wiley.com/doi/epdf/10.1111/gec3.12421

F. Ferretti, 2021, "History of Geography (not identical to historical geography)", in D. Richardson et al. The Wiley-AAG International Encyclopedia of Geography: People, the Earth, Environment, and Technology. Hoboken: Wiley and AAG, https://onlinelibrary.wiley.com/doi/10.1002/9781118786352.wbieg2105 [Pre-Print Author version] 
- Jöns, H., Monk, J., \& Keighren, I.M. (2017). Introduction: toward more inclusive and comparative perspectives in the histories of geographical knowledge. The Professional Geographer, 69(4), 655-660.

- Keighren, I.M. (2018). History and philosophy of geography II: The excluded, the evil, and the anarchic. Progress in Human Geography, 42(5), 770-778.

- Keighren, I.M., Abrahamsson, C. \& Della Dora, V. (2012). On canonical geographies. Dialogues in Human Geography, 2(3), 296-312.

- Livingstone, D. (1993). The geographical tradition. Oxford: Blackwell.

- Meeteren, M.V. \& Sidaway, J.D. (2020). History of geography. In A. Kobayashi (Ed.), International Encyclopedia of Human Geography (vol. 7, pp. 37-44). London: Elsevier (2nd edition).

- Paiva, D. \& Oliveira, F.R. (2020). Luso-Brazilian geographies? The making of epistemic communities in semi-peripheral academic human geography. Progress in Human Geography, early view, doi: 10.1177/0309132520923062

- Springer, S. (2016). The anarchist roots of geography: towards spatial emancipation. Minneapolis: Minnesota University Press.

\section{Further Readings}

Bowd, G. \& Clayton, D. (2019). Impure and worldly geography: Pierre Gourou and tropicality. London: Routledge.

Cresswell, T. (2013). Geographic thought, a critical introduction. Chichester: Wiley-Blackwell. Davies, A. (2019). Geographies of anticolonialism: Political networks across and beyond South India, c. 1900-1930. Hoboken: Wiley.

Driver, F. (2001). Geography militant, cultures of exploration and empire. Oxford : Blackwell,. Ferretti, F. (2018). Anarchy and geography. Reclus and Kropotkin in the UK. Abingdon: Routledge.

Jazeel, T. (2019). Postcolonialism. London: Routledge.

F. Ferretti, 2021, "History of Geography (not identical to historical geography)", in D. Richardson et al. The Wiley-AAG International Encyclopedia of Geography: People, the Earth, Environment, and Technology. Hoboken: Wiley and AAG, https://onlinelibrary.wiley.com/doi/10.1002/9781118786352.wbieg2105 [Pre-Print Author version] 
Jazeel, T. \& Legg, S. (2019) (Eds.) Subaltern Geographies. Athens: The University of Georgia Press.

Strabon (1969). Géographie, tome I. Paris: Les Belles Lettres.

\section{Key Words}

History of Geography; Critical Theory; Spatial Thinking; Transnationalism

F. Ferretti, 2021, "History of Geography (not identical to historical geography)", in D. Richardson et al. The Wiley-AAG International Encyclopedia of Geography: People, the Earth, Environment, and Technology. Hoboken: Wiley and AAG, https://onlinelibrary.wiley.com/doi/10.1002/9781118786352.wbieg2105 [Pre-Print Author version] 